\title{
Correction to: Effect of Endoxylanase and Iron Oxide Nanoparticles on Performance and Histopathological Features in Broilers
}

\author{
Hamza Rehman ${ }^{1}$ (D) Muzamal Akram ${ }^{1} \cdot$ Mubin Mustafa Kiyani ${ }^{1,2} \cdot$ Muhammad Talha Yasin $^{1} \cdot$ Abdul Ghani $^{1}$. \\ Javed Iqbal Saggu ${ }^{3}$. Syed Sajid Hussain Shah ${ }^{4} \cdot$ Zafar Mahmood Khalid $^{1}$. Syed Ali Imran Bokhari ${ }^{1}$
}

Published online: 30 April 2020

(C) Springer Science+Business Media, LLC, part of Springer Nature 2020

\section{Correction to: Biological Trace Element Research} https://doi.org/10.1007//12011-019-01737-z

The original version of this article unfortunately contained a mistake. The name of "Muhammad Talha Yasin" is now corrected in the author group of this article.

Publisher's Note Springer Nature remains neutral with regard to jurisdictional claims in published maps and institutional affiliations.

The online version of the original article can be found at https://doi.org/ 10.1007/s12011-019-01737-z

Hamza Rehman

hamzarehman51@gmail.com

1 Department of Bioinformatics and Biotechnology, International Islamic University, Islamabad, Pakistan

2 Riphah College of Rehabilitation Sciences, Riphah International University, Islamabad, Pakistan

3 Department of Physics, Quaid-i-Azam University, Islamabad, Pakistan

4 Department of Pathology, Northern Border University, Arar, Saudi Arabia 